\title{
Sumô: esporte de japonês em Ivoti/ RS
}

\author{
Josiana Aụala Ledur ${ }^{1}$ \\ Alice Beatriz Assmann² \\ Janice Zarpellon Mazo3
}

\section{RESUMO}

Na colônia japonesa da cidade de Ivoti, no Rio Grande do Sul, destacam-se as práticas corporais de lutas e, dentre estas, o sumô. O presente estudo tem como objetivo investigar como se sucedeu a prática do sumô em Ivoti, desde as primeiras manifestações, na década de 1960, até meados da década de 2010. Para esse fim, foram analisadas fontes impressas, iconográficas e uma fonte oral. A partir do cotejamento e da interpretação das informações foi possível depreender que, através da prática do sumô, de suas representações e adaptações, os nipo-brasileiros de Ivoti buscaram preservar práticas culturais de seus antepassados, vinculando a arte marcial específica, bem como os momentos sociais atrelados a ela, a uma tradição familiar. Neste cenário, a Associação Cultural e Esportiva Nipo-Brasileira de Ivoti (ACENB) constitui-se em local privilegiado para a promoção do sumô, bem como à manutenção e negociação de representações de identidade.

Palavras-chave: Sumô. Luta. História do esporte. Nipo-brasileiros. Imigrantes japoneses

1 Mestre em Ciências do Movimento Humano pela Universidade Federal do Rio Grande do Sul (UFRGS). Porto Alegre/Rio Grande do Sul, Brasil. Email: josiled@hotmail.com

2 Doutoranda no Programa de Pós-Graduação em Ciências do Movimento Humano (ESEFID/UFRGS). Porto Alegre/Rio Grande do Sul, Brasil. Email: alice.assmann@gmail.com

3 Doutora em Ciências do Desporto. Professora associada da Escola de Educação Física, Fisioterapia e Dança (ESEFID) da Universidade Federal do Rio Grande do Sul (UFRGS). Porto Alegre/Rio Grande do Sul,Brasil. Email: janice.mazo@ufrgs.br

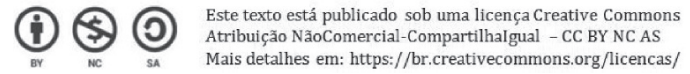




\title{
Sumo: japonese sport in Ivoti/ RS
}

\begin{abstract}
In the Japonese colony of the city Ivoti, Rio Grande do Sul, the corporal practices of wrestling stand out, among them sumo. The present study aims to investigate how the the practice of sumo occurred in Ivoti, since the firsts manifestations, in the 1960s, until the the mid-2010. For this purpose, printed sources, iconographic sources and an oral source were analyzed. From the collating and interpretation of the information it was possible to understand that, through the practice of sumo and its representations and adaptations, the Japanese-Brazilians of Ivoti sought to preserve cultural practices of their ancestors, linking the specific martial art, just as social moments tied to it, to a family tradition. In this scenario, the Associação Cultural e Esportiva Nipo-Brasileira de Ivoti (ACENB) appears as a privileged space to the development of sumo and the maintenance and negotiation of identity representations.
\end{abstract}

Keywords: Sumo. Wrestling. History of sport. Japonese-brazilians. Japonese immigrants

\section{Sumo: deporte japonés en Ivoti/ RS}

\section{RESUMÉN}

En la colonia japonesa de la ciudad de Ivoti, en Rio Grande do Sul, destacan las prácticas corporales de luchas y, entre ellas, el sumo. El presente estudio tiene como objetivo investigar cómo se sucedió la práctica del sumo en Ivoti, desde las primeras manifestaciones, en la década de 1960, hasta mediados de la década de 2010. Para ese fin, se analizaron fuentes impresas, iconográficas y una fuente oral. A partir del cotejo y de la interpretación de las informaciones fue posible deducir que, a través de la práctica del sumo, de su s representaciones y adaptaciones, los nipo-brasileños de Ivoti buscaron preservar prácticas culturales de de sus antepasados, vinculando el arte marcial específico, así como los momentos sociales articulados con ella, a una tradición familiar. En este escenario, la Associação Cultural e Esportiva Nipo-Brasileira de Ivoti (ACENB) aparece como local privilegiado para la promoción del sumo y el mantenimiento y negociación de representaciones de identidad.

Palabras-clave: Sumo. Lucha. Historia del deporte. Nipo-brasileños. Inmigrantes japoneses

\section{INTRODUÇÃO}

No cenário do associativismo esportivo sul rio grandense, os nipo-brasileiros parecem ter atuado de forma mais expressiva na difusão das práticas corporais de luta. Este 
entendimento deve-se em parte à atuação de professores de karate-do e judô em clubes e academias militares, principalmente durante as décadas de 1950 a 1980 (NUNES, 2011; FROSI, 2012; LEDUR, 2013). Todavia, há vestígios de práticas corporais de luta, desde as primeiras décadas do século XX, quando aportou no Brasil o navio Kasato Maru, no ano de 1908, trazendo imigrantes japoneses (NUNES, 2011; SUZUKI; MIRANDA, 2008). Desde então, os imigrantes japoneses buscaram preservar suas tradições e práticas culturais, especialmente nas colônias ${ }^{4}$, onde se estabeleceram, para se sentirem próximos de sua terra natal (JICA, 2003; SUZUKI; MIRANDA, 2008).

No Rio Grande do Sul, a chegada de imigrantes japoneses foi tardia e em número reduzido quando comparado aos imigrantes alemães e italianos (NETO; BEZZI, 2008). Embora indícios apontem que os primeiros japoneses chegaram ao estado nos anos de 1920 e que precursoras tentativas de colonização foram iniciadas na década de 1930, a data oficialmente reconhecida como o princípio da imigração japonesa no Rio Grande do Sul é 20 de agosto de 1956 (GAUDIOSO, 2011). A escolha da data comemorativa se deve a vinda de muitas famílias japonesas para o Brasil depois da Segunda Guerra Mundial (1939-1945), para refazerem suas vidas.

Após uma década do ano oficial da imigração japonesa no Rio Grande do Sul, em 1966, 26 famílias desta nacionalidade chegaram ao Brasil e se dirigiram para o estado do Rio Grande do Sul, estabelecendo-se em Ivoti. Esta cidade, assim como a maioria dos municípios da região do Vale do Rio dos Sinos, tem uma expressiva presença de teuto-brasileiros. Desde a instalação dos imigrantes japoneses, também passou a ser conhecida como sede da maior colônia japonesa do Rio Grande do Sul em termos de número de habitantes (GAUDIOSO, 2011). Em Ivoti, os imigrantes japoneses começaram a promover práticas corporais, dentre elas, destaca-se o sumô.

O presente estudo tem como objetivo investigar como se sucedeu a prática do sumô em Ivoti, desde as primeiras manifestações até meados da década de 2010. Justifica-se a escolha desta prática de luta por ter sido a primeira prática esportiva nipo-brasileira disseminada em Ivoti, a qual é desenvolvida até os dias de hoje na localidade. Além disso, conforme levantamento da produção científica no Brasil na área da Educação Física, apresentado por Ledur (2017), a ocorrência de publicações acadêmicas sobre o sumô ainda é escassa. A autora (2017) localizou apenas um artigo que trata especificamente desta prática, o qual foi publicado no ano de 2016. Em termos numéricos, o Judô é a prática de luta que tem maior representatividade na produção de teses, dissertações e artigos acadêmicos nos últimos 10 anos (LEDUR, 2017).

4 Segundo Hirata (2006, p. 23), colônia japonesa pode ser entendida como "o conjunto de imigrantes e descendentes japoneses de um determinado espaço geográfico, com tamanhos diferenciados, que podem formar desde uma microrregião até um distrito (...)". E, "podem ou não estar organizadas socialmente ou economicamente através de cooperativas, sindicatos e associações culturais, sociais, assistências ou educacionais" (HIRATA, 2006, p. 23). 


\section{Procedimentos metodológicos}

Este estudo está amparado nos pressupostos teóricos da Nova História Cultural (CHARTIER, 2000; PESAVENTO, 2008), propondo-se decifrar uma realidade vivida no passado por meio das suas representações, a fim de compreender como "tal realidade social foi construída, pensada, dada a ler" (CHARTIER, 2000, p. 16). Busca-se "chegar àquelas formas discursivas e imagéticas por meio dos quais os homens expressaram a si próprios e o mundo" (PESAVENTO, 2008, p. 42). Para tal, foram coletadas fontes impressas, iconográficas e oral.

As fontes impressas adotadas neste estudo foram: Atlas do Esporte no Brasil, Atlas do Esporte no Rio Grande do Sul, jornais, livros, revistas e informativos da ENKYOSUL. Também, foram realizadas visitas periódicas a Biblioteca Pública Municipal Laís Helena Bruck Mundstock da cidade de Ivoti, no Memorial da Colônia Japonesa de Ivoti $^{5}$ e no acervo da Associação de Assistência Nipo Brasileira do Sul (ENKYOSUL). Vale mencionar que a ENKYOSUL, fundada em 1969, é uma das associações de maior representatividade dos nipo-brasileiros nos estados do Rio Grande do Sul e de Santa Catarina. Nesse local, foi possível consultar fontes documentais, tais como atas, diários oficiais e jornais informativos que circulam entre os associados.

Dentre os periódicos consultados destaca-se o Jornal de Ivoti, fundado em 1985, o Jornal Livre Expressão, criado em 1995, e O Diário da Encosta da Serra, que iniciou suas atividades em 1992. Além destes, a biblioteca municipal possui em uma pasta avulsa jornais como o NH, de Novo Hamburgo, e algumas edições do jornal Zero Hora de Porto Alegre. As fontes impressas foram submetidas a análise documental segundo Cellard (2008).

Para além da utilização de fontes impressas, também foram empregadas nesse estudo fontes iconográficas, como fotografias e ilustrações encontradas em periódicos. Segundo Kossoy (2001, p. 36), "toda fotografia/imagem tem sua origem a partir do desejo de um indivíduo que se viu motivado a congelar em imagem um aspecto dado do real, em determinado lugar e época". Dessa forma, as imagens pertencem a um contexto e são registros que nos possibilitam realizar um diálogo com outras fontes históricas.

Ainda, foi produzida uma fonte oral por meio de entrevista semiestruturada, com base nos pressupostos da História Oral (MEIHY, 2002). Destacamos aqui também como parte dos procedimentos éticos, que o uso de entrevistas neste estudo encontra amparo em um projeto maior do qual é integrante, intitulado "Cenários Históricos e Socioculturais dos Esportes e da Educação Física no Rio Grande do Sul - Brasil", aprovado no Comitê de Ética em Pesquisa da UFRGS pelo número 27331. O sujeito entrevistado na pesquisa é o Sr. Sérgio Fukunaga, que iniciou a pratica do sumô ainda na década de 1970. Depoimentos permitem que atores sociais expressem o que para eles, dentre as experiências vividas, deve ser memorável. Cabe ao entrevistador, ao coletar as informações, partir da premissa

5 O Memorial da Colônia criado em 2011 também assumiu um papel de difusor dos aspectos culturais, alimentares, dos festejos, da religião, do lazer e do esporte. Para mais informações sobre a construção do Memorial da Colônia Japonesa de Ivoti ver Dilly e Gevehr (2014). 
que a memória é seletiva, não sendo possível, portanto apreendermos uma memória, mas sim captar fragmentos que a constituem (MATOS; SENNA, 2011).

Os tópicos que seguem compreendem o resultado do cotejamento e da interpretação das informações garimpadas através das diferentes fontes coletadas, a fim de construir uma versão argumentada sobre a prática do sumô na cidade de Ivoti, Rio Grande do Sul.

\section{Uma prática de luta: o sumô}

O sumô é uma arte marcial de ascendência japonesa, que conserva em sua prática aspectos de antigos rituais religiosos. Sua história envolta em lendas, nos remete a um passado longínquo, que relaciona seus primeiros combates a um tempo inscrito faz mais de dois mil anos (CANTARINO FILHO; MIURA, 2010; DARIDO, 2011). Dentre as possíveis versões sobre a emergência da prática, está a descrita no livro de crônicas antigas Kojiki referente ao ano 712 d.C., em que o destino das ilhas japonesas repousou sobre o resultado de uma luta entre dois deuses, Takemikazuchi e Takeminakata (HALL, 1997).

Durante os séculos referentes aos período Nara (645-794) e Heian (794-1185), esta modalidade era conhecida como Sechiezumo ${ }^{6}$ e cerimonialmente realizada uma vez por ano, no sétimo dia do sétimo mês na corte imperial, tendo como seus principais espectadores ilustres figuras da realeza que representavam o governo japonês. As partidas eram realizadas em santuários xintoístas e dedicadas aos deuses, na esperança de obterem boas colheitas (HALL, 1997).

Sob o patrocínio do imperador, a luta ganhou uma importância tão grande que, para garantir a qualidade do evento, aos representantes do governo era atribuída a tarefa de selecionar indivíduos que se destacassem por sua força e porte físico para participar no evento. Seu destaque estendeu-se ao período Kamakura (1185-1334), que foi permeado por guerras sangrentas travadas no território japonês, promovidas por uma espécie de ditadura militar que ficou conhecida como shogunato ${ }^{7}$. Consta que, neste período, o sumô foi implementado como parte do programa de treinamento dos militares, tendo em vista que nos primórdios as partidas eram bastante violentas, caracterizadas por uma combinação de luta livre, boxe e judô, visando forçar o inimigo ao chão, onde este poderia ser facilmente imobilizado. Para além dos princípios de lutas operavam, em paralelo, a música, a leitura de poesia, danças sagradas e encenações de artes dramáticas (HALL,1997).

6 Sechiezumo é o sumô praticado na corte imperial no Japão antigo. Servia tanto como ritual religioso quanto entretenimento.

7 Durante o período Kamakura (1185-1334) o único poder reconhecido na maior parte do Japão era exercido por uma espécie de governo militar, o bakufu. O líder máximo desse sistema era o shogun, um título equivalente ao de um generalíssimo, ou seja, o supremo comandante (SOMMA, 2005). 
Na era Tokugawa (1603-1868) o sumô tornou-se profissional, financiado pelos daimyo ${ }^{8}$, juntamente com o apoio da população. Deste momento em diante, a estrutura organizacional do sumô moderno consolidou-se. Todavia, cabe salientar que até os dias de hoje a prática carrega elementos e significados dos primórdios de sua emergência em terras japonesas. Dentre esses, a crença no sumô como uma prática que, além de trazer força física, fortalece o espírito e contribui para o controle mental (DARIDO, 2011).

Mesmo que compartilhe sentidos comuns, o sumô não é vivenciado de uma só maneira. Para termos uma dimensão, no Japão, ele ocupa o posto mais alto na preferência dos nipônicos, tal como é o futebol para os brasileiros. O sentido atrelado à prática é evidenciado na exaltação aos lutadores das categorias profissionais de sumô, nomeados Yokozuna ${ }^{9}$, que possuem hoje status equivalentes aos de ministros de estado. Os atletas que conseguem alcançar este alto patamar são enaltecidos quase como divindades no país, que já conta com campeonatos profissionais desde a década de 1920.

Os mais importantes torneios da atualidade ocorrem seis vezes por ano, com cerca de oitocentos lutadores. Nas principais disputas, que acontecem em Tóquio, os troféus são entregues pelo primeiro ministro japonês e, em ocasiões muito especiais, pelo próprio imperador (DARIDO, 2011), salientando a relevância social e cultural destes eventos. Privilégios que não se assemelham em nada com a realidade dos sumotoris ${ }^{10}$ amadores, que representam a maioria dos praticantes no mundo, incluindo os lutadores brasileiros.

A despeito de o sumô constituir-se em uma novidade para muitos, o primeiro registro de campeonato realizado no Brasil remete ao ano de 1914, na colônia de Guatapará, um dos maiores redutos de imigrantes japoneses do início do século XX, que ficava localizada no interior do estado de São Paulo. Handa (1987) conta que, nos núcleos de japoneses estabelecidos no Brasil nas primeiras décadas do século XX, era comemorado o aniversário do imperador japonês e dentre as práticas culturais realizadas no festejo, além da competição undôkai ${ }^{11}$ encontrava-se por vezes também teatro e sumô.

De lá para cá, os paulistas vêm conseguindo manter esta prática milenar viva, salientando sua realização em locais como os bairros Liberdade e Bom Retiro. Este último destaca-se por possuir o primeiro dohyo (ringue) criado no Brasil (VERÍSSIMO, 2015). Demais evidencias estão vinculadas a organizações esportivas como a Federação Paulista de Sumô (FPS), fundada em 1962, e da Confederação Brasileira de Sumô (CBS), criada em 1998 (CANTARINO FILHO; MIURA, 2010). O Brasil é ainda um dos fundadores da Federação Internacional de Sumô (IFS), criada em 1992, além de realizar a primeira competição mundial amadora fora do Japão em 2000, no Parque Ibirapuera, em São Paulo (IFS, 2017). Nesse cenário, ressalta-se que os atletas brasileiros já conquistaram diferentes títulos mundiais nas categorias masculina e feminina. Dentre eles, os títulos mundiais

8 Senhores feudais das províncias.

9 O mais alto estágio que um atleta pode alcançar no Sumô.

10 Forma como são chamados os lutadores de Sumô.

11 Undokai é uma gincana esportiva familiar criada no Japão durante o governo Meiji (1868-1912), sua presença no Brasil remete ao início do século XX com a chegada dos primeiros imigrantes. Ver mais em Ledur (2017). 
conquistados por Cláudio Ikemori na classificação peso leve em 2004 e Fernanda Pereira no peso pesado do sumô feminino (Shinzumo) em 2005, em Rieza na Alemanha. Luciana Montgomery Watanabe, no ano de 2010, conquistou medalha de bronze no Campeonato Mundial de sumô no Japão.

Como parte da agenda do sumô no Brasil são realizados, anualmente, no mês de julho, eventos combinados como o Campeonato Brasileiro Masculino, Campeonato Brasileiro Feminino, Campeonato Sul-Americano Masculino e Campeonato Sul-Americano Feminino de Sumô, sediados no Ginásio de Sumô do Conjunto Esportivo e Cultural Brasil/ Japão, em Bom Retiro, São Paulo. A despeito de nenhum brasileiro ter alcançado o grau de Yokozuna, o paulista Ricardo Sugano faz parte de uma classe de sumotoris no Japão, a dos makuuchis, a qual é vista como distinta no país. Ricardo utiliza o nome de Kaisei Ichiro, e nos campeonatos usa um kesshou-mawashi ${ }^{12}$, um cinto cerimonial pré-luta com a bandeira brasileira e um bordado representando o Cristo Redentor (SANTOS, 2012).

Embora existam organizações que regulamentam e tentam difundir esta modalidade, ainda há os que estranham, ou fazem piadas sobre o biotipo dos lutadores ou mesmo com relação ao tipo de vestimenta utilizada pelos mesmos durante as competições, conhecida como mawashi ${ }^{13}$. Estas posturas equivocadas, infelizmente, ocorrem em diversos meios e são em parte fortalecidas pela mídia. Como exemplo, no ano de 2014, em programa televisionado pela emissora Rede Globo, um convidado questionou de forma rude o uso do mawashi. Ao se dirigir a dois praticantes que haviam sido convidados para fazer uma demonstração indagou: "Eu tenho uma curiosidade, por favor. É o seguinte, aquela roupa ridícula tem alguma função"? (SUMÔ, 2014). Este comentário, que foi seguido de risos, indica que seria proveitoso, principalmente para fins de desmistificação, uma maior divulgação em nosso país a respeito do sumô, que além de ter uma rica história, há muitas décadas possui atletas dessa modalidade de luta, contando até com campeonatos nacionais nas categorias adulto e infanto-juvenil.

Mocarzel (2016, p. 110) alude que, "os sumotoris em diversos momentos são alvo de muita caricatura popular", o que diminui a procura pelo esporte. Para este autor (2016), o desconhecimento e a ignorância por parte da mídia e dos profissionais de educação

12 O Keshō-Mawashi Modern sumo wrestlers in top division ring entrance ceremony, wearing keshō-mawashi é um cinto utilizado por lutadores de divisões superiores como a Wrestlers in the two upper divisions, and , are allowed to wear a second ceremonial keshō-mawashi during their ring entering ceremony. makuuchi e jūryō, durante a cerimônia de entrada no ringue. The silk 'belt' opens out at one end into a large apron which is usually heavily embroidered and with thick tassels at the bottom. Este "cinto" de seda mais largo na parte inferior se abre como um avental grande, a quase tocar nos tornozelos. Geralmente possui muitos bordados, também The keshō-mawashi may advertise the produce of a sponsor of the rikishi (for example Bulgarian was sponsored by a Japanese brand of yogurt, "Bulgaria", which was prominently displayed on the front of his keshō-mawashi ) or be a gift from one of the rikishi' s support groups.podendo anunciar o produto de um patrocinador, ou seja, representa um dos grupos de apoio do lutador. No caso de o lutador ser de origem estrangeira (como Ricardo Sugano) a bandeira do país pode estar representada kesshou-mawashi. Popular rikishi may be given many of these keshō-mawashi .

13 Espécie de cinto protetor que os lutadores de sumô utilizam durante a prática da arte marcial. Além de representar uma luta sem armas, serve tanto para proteger os órgãos genitais, como para facilitar golpes de agarramento facilitando a retirada do oponente para fora do dohyo. 
física "atrapalha imensamente o desenvolvimento do Sumô" no Brasil e em outras partes do mundo (p. 110). A falta de conhecimento sobre o sumô, possivelmente, contribui para que os campeonatos ocorram de forma mais tímida e localizada em cidades que constituem colônias japonesas ou arredores. Em parte, esta situação ocorre devido à falta de visibilidade do sumô. Outro aspecto diz respeito as condições pouco favoráveis para a realização e participação em campeonatos. A maioria dos atletas enfrenta dificuldades financeiras, muitas vezes tirando dinheiro do próprio bolso para competir. Fato que ocorreu com a seleção brasileira de sumô na tentativa de comparecer na edição de 2014 dos jogos mundiais realizados em Taiwan. Os lutadores fizeram rifas e tentaram patrocínios diversos para amenizar os custos da viagem (RODRIGUES JÚNIOR, 2012). No entanto, essa não é uma exclusividade dos sumotoris, uma vez que acontece também com muitas outras modalidades esportivas no Brasil. Atletas brasileiros que praticam esporte sem patrocínio, o fazem por "amor à camisa", ou melhor dizendo, ao mawashi.

\section{O sumô em Ivoti: reconstruindo histórias}

No Rio Grande do Sul, o sumô emergiu em meados de 1960, difundindo-se, principalmente, nas colônias japonesas como Ivoti e Itati e em localidades que possuem centros destinados à prática como as cidades de Nova Petrópolis, São Leopoldo, Esteio e Glorinha. Este movimento tem sido viabilizado através da atuação de associações como a ENKYOSUL, a Associação Cultural e Esportiva Nipo-Brasileira de Ivoti (ACENB) e a Associação Cultural Esportiva de Itati/RS (ACEI). Importa ressaltar que não existe no Rio Grande do Sul uma federação própria de sumô.

Desde a manifestação da prática no estado, a preocupação com a participação em eventos esportivos estava presente. O primeiro Campeonato Gaúcho de Sumô foi realizado em 1969, pela iniciativa da ENKYOSUL, mas desde 1961 os atletas sul-rio-grandenses têm participado de campeonatos brasileiros. Inicialmente, eram organizados pela Federação Paulista de Sumô e na atualidade pela Confederação Brasileira de Sumô. Da realização do primeiro campeonato até os dias atuais, que contabilizam mais de 50 anos, esta pratica de luta se difundiu entre descendentes de japoneses e não descendentes no Rio Grande do Sul.

No estado, atletas da modalidade estão ganhando visibilidade na cena do esporte nacional e mundial, por meio de conquistas de títulos em campeonatos brasileiros, sul-americanos e nos campeonatos mundiais, tanto em equipe como individual. Como parte desta "família sumô", termo utilizado por atletas sul-rio-grandenses (FUKUNAGA, 2017), podemos citar Carlos Alberto Rauch, de Nova Petrópolis, que participou do World Games, na categoria adulto, realizado na Alemanha, em 2009, sendo esta a primeira participação de um atleta brasileiro nesta competição. Os irmãos Yuuki e Isamu Sato, da cidade de Esteio, também se destacam nas competições, sendo que os dois obtiveram, respectivamente, o primeiro e o segundo lugar do $53^{\circ}$ Campeonato Brasileiro de Sumô, realizado em São Paulo em julho de 2014. Tanto Yuuki como Isamu praticam o sumô desde os quatro anos de idade, uma prática cultural transmitida de pai para filhos. Antenor Sato, o pai, disputa o 
campeonato brasileiro na categoria adulto há 25 anos e ficou em $3^{\circ}$ lugar no Campeonato Mundial de Sumô em 1998. No Rio Grande do Sul existem apenas quatro dohyos - Itati, Gravataí, Ivoti e Nova Petrópolis (FUKUNAGA, 2017) - e a família Sato inteira treina no dohyo localizado na Colônia Japonesa de Ivoti (IRMÃOS SATO..., 27 ago. 2014).

A fim de auxiliar atletas sul-rio-grandenses, tendo em vista as constantes crises financeiras que acometiam a ENKYOSUL, foi criada em 2003 a Associação Neo Petropolitana de Sumô e Associação de Sumô no Vale dos Sinos, que tem como presidente Renê Crespo ${ }^{14}$. Crespo, em entrevista ao Jornal Novo Hamburgo durante a Feira da Colônia Japonesa de Ivoti em 2016, comentou que "o esporte japonês mais antigo tem atraído participantes que não tem descendência japonesa também" (MELLO, 2016). As primeiras evidências encontradas nas fontes consultadas acerca do Sumô em Ivoti fazem parte do Jornal Livre Expressão, fundado na década de 1990, abordando o contexto de campeonatos.

A partir de uma reportagem, acompanhada por dez fotos distribuídas entre o dohyo, praticantes e suas respectivas equipes e público presente, o jornal trouxe a realização do $1^{\circ}$ Campeonato de Sumô na Colônia Japonesa de Ivoti. O campeonato, ocorrido no dia 26 de fevereiro de 1996, contou com patrocínio de representantes do comércio local, de compatriotas de Nova Petrópolis e de uma agência de turismo de Porto Alegre. Quanto aos lutadores presentes estavam os moradores da colônia de Ivoti, São Leopoldo, Nova Petrópolis e Gravataí. As equipes divididas em categorias infantil, juvenil e adulta animaram o público com suas disputas e demonstrações de ataques com grande velocidade. "Dos cinquenta países que praticam o Sumô, tecnicamente o Brasil é segundo do ranking, perdendo apenas para o Japão" (CAMPEONATO DE SUMÔ..., 28 fev. 1996, p. 6). Dentre as imagens veiculadas sobre o campeonato, selecionamos duas, cujas particularidades nos permitiram refletir sobre os sentidos apreendidos através de representações da prática cultural do sumô. Abaixo se encontra a figura publicitária utilizada pela Associação Cultural Esportiva Nipo-brasileira de Ivoti para o evento.

14 Renê Crespo, natural de Novo Hamburgo por muito tempo representou a Colônia Japonesa de Ivoti. Acumula títulos como: campeão mundial em 1991, campeão gaúcho nove vezes e campeão brasileiro quatro vezes. 


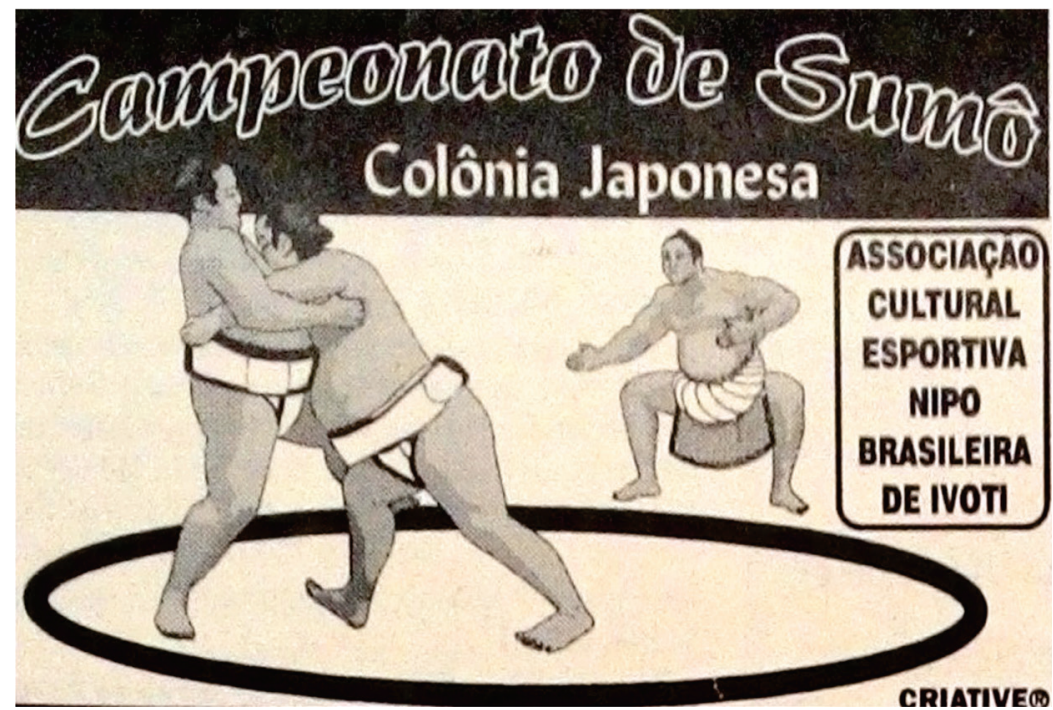

Imagem 1: $1^{\circ}$ Campeonato de Sumô da Colônia Japonesa de Ivoti. Fonte: CAMPEONATO DE SUMÔ..., 28 fev. 1996.

Nesta primeira imagem está representada simbolicamente uma disputa de sumô nos moldes da prática realizada no país de ascendência. Ao ocupar o topo da página, superando as demais em tamanho e detalhes, a imagem parece intentar a construção de sentidos, direcionando o olhar do espectador para determinada relação entre uma prática esportiva específica, o sumô, e a identidade cultural de um grupo étnico específico. Nesse grupo, a identidade cultural os distingue socialmente de outros grupos e, ao mesmo tempo, produz um sentido de coesão social vinculado a ideia de pertencimento. $E$, assim, suscita "a identificação da parte com o todo, do indivíduo frente a uma coletividade", no mesmo passo que "estabelece a diferença" (PESAVENTO, 2008, p. 89). Contudo, assim como enfatiza Pesavento (2008, p. 89), é importante considerar "não a constatação da diferença [...], mas sim a maneira que se constrói pelo imaginário social essa diferença". Através da imagem e das apropriações nela inscritas, a associação se diferencia de outros grupos, como os teuto-brasileiros de Ivoti, e se localiza no espaço social afirmando uma descendência japonesa. Ressalta-se que na ilustração os personagens utilizam o penteado conhecido como chonmage ou apenas mage ${ }^{15}$ (DARIDO, 2011) e o mawashi, incluindo a versão kesshou, que parece ser a vestimenta do lutador fora da área do dohyo. Destaca-

15 Chonmage ou mage é uma forma de penteado tradicional japonês utilizado pelos sumotoris indicando o estágio em que o lutador se encontra. Só pode ser cortado na cerimônia de aposentadoria do lutador (DARIDO, 2011). 
mos esses detalhes, pois o uso do mage e do kesshou, apesar de fazerem parte do esporte profissional, não são exigências da prática esportiva por amadores, tal como ocorre em Ivoti, no Rio Grande do Sul, o que pode ser observado na fotografia abaixo.

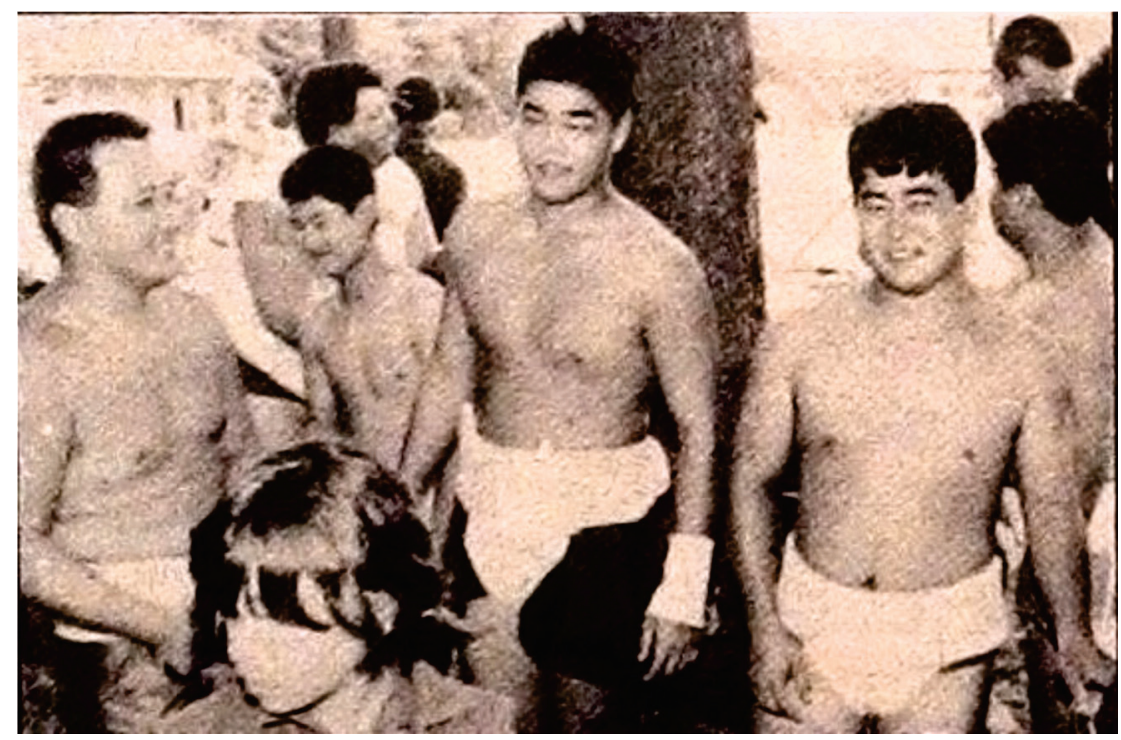

Imagem 2: Equipes descontraídas durante um campeonato de sumô. Fonte: CAMPEONATO DE SUMÔ..., 28 fev. 1996.

Nesta imagem, lutadores que participaram do $1^{\circ}$ Campeonato de Sumô na Colônia Japonesa de Ivoti utilizam o mawashi por cima de bermudas ou sungas. No Brasil, os homens têm a opção de escolher como lutar em campeonatos regionais: com a sunga ou sem. Conforme aponta Higuchi (2011), em campeonatos estaduais e nacionais, é uma exigência o uso de uma sunga antes de colocar o mawashi. Esse padrão brasileiro é mantido, segundo Higuchi (2011), por ser considerado uma característica que remete aos antepassados imigrantes que usavam short ou sunga antes de colocar este cinto protetor, pois tinham de improvisar o material utilizado na fabricação desta peça, que normalmente é de algodão, utilizando sacos de arroz e outros materiais inadequados, que rompiam com facilidade. Para Sérgio Fukunaga, o uso da vestimenta por baixo do mawashi, está também atrelado ao espaço social: "O pessoal já não aceita usar o mawashi e imagina tu usares sem. A gente usa uma sunga, um calção por uma questão talvez até um pouco de vergonha, e não vai ser muito bem aceito culturalmente no Brasil" (FUKUNAGA, 2017). 
Este estranhamento da prática esportiva do sumô por parte dos "outros" é também destacado por Handa (1987, p. 246):

Os brasileiros nunca tinham visto uma luta em que os competidores usavam apenas o fundoshi, e embora fossem em pequeno número eles assistiam, admirados. O juiz ordenava matta, matta em japonês e dizem que os brasileiros ficavam apavorados porque em português essa palavra parecia significar "mate", e não "espere", que é o sentido de matta em japonês.

Este relato, referente aos primeiros núcleos de japoneses no Brasil, reitera as afirmações de Fukunaga. Ademais, demonstra que nas primeiras aparições do sumô em terras brasileiras, procurava-se manter a tradição dos sumotoris de utilizar somente a vestimenta própria da prática, o mawashi ou um fundoshi ${ }^{16}$ de seda. Isto é corroborado por uma imagem apresentada pelo autor (1987) de uma disputa de sumô no núcleo Tóquio, em 1918. Handa (1987) cita ainda as dificuldades quanto ao estranhamento da língua, incompreensível para os "brasileiros". Tal circunstância, provavelmente, contribuía para o "pequeno número" de espectadores não japoneses nas disputas. Da mesma maneira, favoreceram as adaptações realizadas para a prática, como a utilização do calção, a fim de serem "aceitas" no Brasil.

Santos, Doll e Gaudioso (2003, p. 54) inferem que em Ivoti os japoneses transformaram "muitas coisas na cultura brasileira, da mesma maneira que a sua cultura nipônica foi modificada. Mesmo existindo ainda algumas dificuldades, percebemos que o japonês conseguiu criar e administrar o seu espaço na cultura brasileira". Em Ivoti, representações e práticas foram negociadas em relações constantes de proximidade e distanciamento entre os indivíduos e suas coletividades. Estas negociações são domínios de disputas próprias do contato cultural estabelecido entre as diferentes identidades e promovem, assim, modificações e ressignificações, como é verificado na fotografia a seguir.

16 Fundoshi é uma espécie de "tanga" ou roupa de baixo utilizada pelos homens. O mawashi consiste em um fundoshi de seda utilizado pelos sumotóris (FRÉDERIC, 2008). 


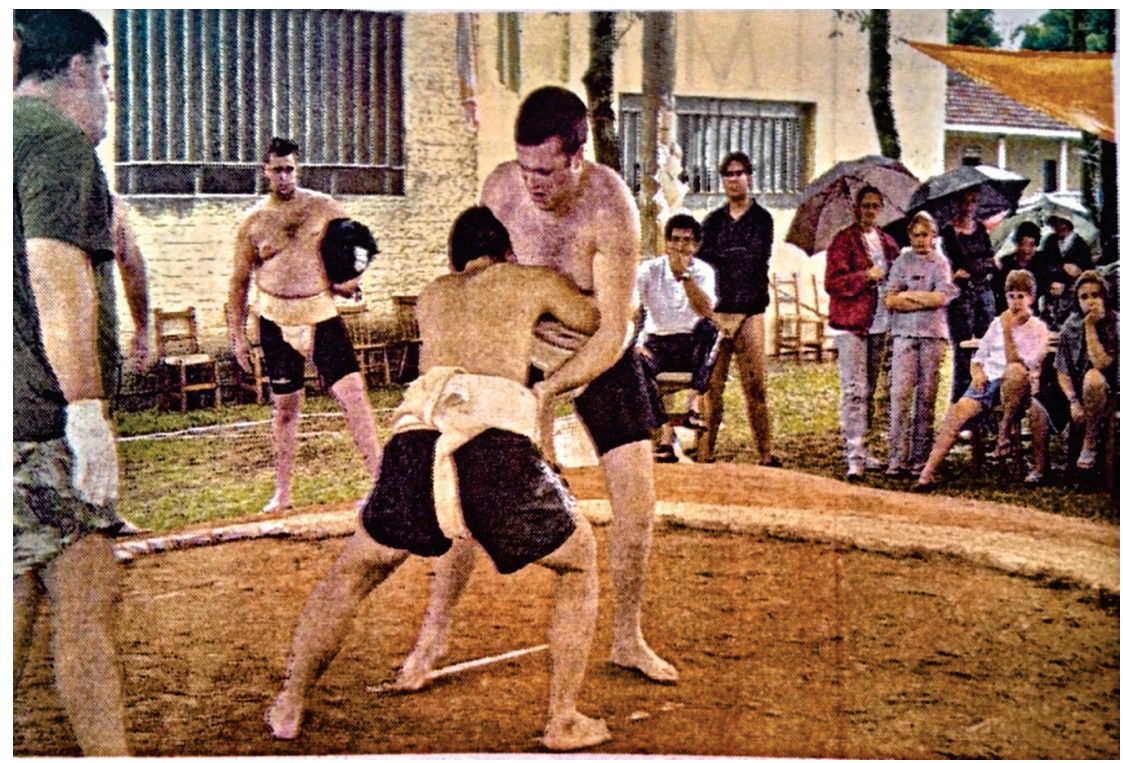

Imagem 3: Luta no campeonato de sumô de 2003.

Fonte: CAMPEONATO DE SUMÔ, 28 abril 2003.

Na imagem acima, veiculada pelo jornal O Diário, é possível observar uma luta de sumô no dohyo da associação esportiva da Colônia Japonesa de Ivoti. Este espaço tem sido palco de diversos eventos e campeonatos do estado do Rio Grande do Sul. Em 2003, a sede da ACENB foi palco de três eventos de sumô: $43^{\circ}$ Campeonato Brasileiro, $3^{\circ}$ Campeonato Feminino e $2^{\circ}$ Campeonato Máster. Nestes eventos, importantes nomes do sumô nacional e internacional compareceram para competir e prestigiar, como Kaneyoshi Ueno, duas vezes campeão brasileiro. Também, esteve presente Carlos Rauch, campeão brasileiro da categoria peso médio (até $115 \mathrm{Kg}$ ) e um dos melhores do mundo, além de outros ex-campeões nacionais.

Nos anos seguintes a associação prosseguiu como espaço de eventos e de congregação de praticantes de diferentes localidades. O 54 Campeonato Estadual de Sumô foi realizado no dia 30 de março de 2014 no dohyo da ACENB, reunindo equipes de Nova Petrópolis, Itati e São Leopoldo, sendo disputado nas categorias: Mirim, Infantil, Adulto Leve, Adulto Médio, Adulto Absoluto, além de uma competição por equipes. Na edição em questão, o destaque foi o atleta Carlos Rauch que levou o título da categoria Adulto Médio para Nova Petrópolis (ESTADUAL DE SUMÔ, 2014, p. 25). Como parte da história do sumô em Ivoti, a sede da Associação Cultural e Esportiva Nipo Brasileira (ACENB) é apresentada pelo Jornal Livre Expressão, já em 1995, como um local de encontro para a comunidade (COLÔNIA JAPONESA, 17 jan. 1995). Além dos campeonatos de sumô e do desenvolvimento de diferentes práticas esportivas como o judô, o local é compartilhado pela comunidade através de outras atividades culturais como exposições e festas. 
Em um banner de divulgação da referida Associação, exposto no Memorial da Colônia Japonesa, é evidenciada a apropriação da prática do sumô enquanto meio de representar uma coletividade. Nesse, dentre tantas práticas culturais e esportivas que poderiam ser selecionadas, uma imagem da prática do sumô realizada por adultos e crianças foi escolhida para dar a ver e a ler uma identidade nipo-brasileira (SOCIAL..., 2016). Ainda, desde 2012 a colônia promove uma feira como forma de divulgar sua cultura e, dentre comidas típicas, produtos coloniais, flores e artesanatos, o sumô recebe especial atenção, reforçando tal inferência. Em 2014, por exemplo, foi disputado um campeonato com mais de 150 lutas durante o dia da feira (FEIRA NA COLÔNIA, 31 mar. 2014). Pode-se inferir que o sumô, em diferentes momentos, assume a função de marcador identitário nipo-brasileiro. É possível que tal apropriação esteja relacionada com o imaginário social construído mundialmente sobre o sumô enquanto prática japonesa. Importa destacar que, para além do sumô, estão presentes na Colônia Japonesa de Ivoti, outras práticas esportivas e corporais distinguidas por representações nipo-brasileiras, como o Gateball, o Judô, o Odori e o Undokai. Dentre estas, segundo as evidências encontradas por Ledur (2017), o sumô, ao lado das práticas corporais de danças chamadas Odori, parece ter sido a primeira prática esportiva desenvolvida pelos recém-chegados imigrantes japoneses na localidade.

No mesmo passo que práticas japonesas, como o sumô, foram ressignificadas, os contatos culturais e as relações tensionadas naquele espaço, também resultaram na apropriação de práticas esportivas percebidas enquanto representação de uma identidade "brasileira", como o futebol. Sobre uma disputa entre dois times de futebol da Colônia Japonesa de Ivoti, em triangular com time da colônia de São Leopoldo, o jornal de Ivoti reforçou: "Cada vez mais os nipônicos estão aderindo ao futebol, que é a grande paixão de milhares de brasileiros e de tantos outros povos do mundo" (A COLÔNIA JAPONESA..., nov.1985, p. 16). O jogo ocorreu em Sapucaia do Sul, no ano de 1985, no campo da empresa Kurashiki e foi promovido pela ENKYOSUL. Anos mais tarde, em 1990, consta como reivindicações da ACENB perante a prefeitura de Ivoti, melhorias no campo de futebol da Colônia e na "praça destinada a esportes de origem nipônica, muito praticados pelos descendentes japoneses de Ivoti" (COLÔNIA JAPONESA..., 20 jun. 1996, p.6). A reportagem citada corrobora a importância dada ao esporte dos "brasileiros", o futebol. Contudo, o destaque é ainda atribuído aos esportes dos "japoneses", aqueles que são "muito praticados" na Colônia, revelando uma intenção. Ademais, o campo é também utilizado para as práticas do Undokai. Tais assertivas, associadas às inferências anteriores, apontam para relações de trocas que foram estabelecidas entre os grupos étnicos. É possível pensar, assim, que para além de estabelecer diferenças, as fronteiras cultuais também provocam transformações e permitem a construção de outras maneiras de se perceber no mundo e atribuir sentido a ele.

Na tentativa de compreender os sentidos atribuídos ao sumô no Rio Grande do Sul e, especialmente, na Colônia Japonesa de Ivoti, nos aproximamos das memórias de Sérgio Fukunaga. A partir de suas recordações apreendemos a produção de significados que partem da compreensão de uma tradição cultural que deve ser preservada. A dedicação às práticas corporais nipo-brasileiras nas comunidades japonesas do estado é percebida 
como meio de representar culturalmente uma tradição familiar, fundamentada em uma identidade étnica. Guiado por sua trajetória na arte marcial do sumô, lembrando ora de sua infância ora de seu envolvimento quando adulto, Sérgio Fukunaga nos apresentou um contexto muito rico, alicerçado na história de sua família, incentivadora da prática "por ser cultural entre eles ter que lutar", como destacou. Ao recordar o passado, mencionou que iniciou seus aprendizados nesta arte marcial entre os seis e sete anos de idade. E, que não era algo opcional: "Não era nem opção, era uma obrigação de continuar a cultura japonesa".

Em Ivoti, logo no começo da colonização japonesa o sumô foi apropriado como uma maneira de preservar a cultura dos antepassados. Antes da criação de um dohyo específico na colônia, segundo Fukunaga (2017), "os antepassados tinham que improvisar um lugar onde eles pudessem treinar, mas não com toda a estrutura que tem agora ali". O significado desta prática, nas palavras de Fukunaga, está atrelado a sentimentos de respeito e amizade e, também, ao reconhecimento de uma herança cultural familiar:

Para mim? Olha, eu desde que me conheço por gente, eu fui introduzido no Sumô. Então, o Sumô, nós chamamos de família Sumô. É uma coisa com muita disciplina respeito, é uma doutrina, é uma arte marcial em que nós vamos fazendo amizades. Por exemplo, eu, a primeira vez que eu fui em um Campeonato Brasileiro foi em 1977. Lá se vão muitos anos de muitas amizades e é isso, tudo dentro da doutrina (FUKUNAGA, 2017, p. 7).

Na opinião de Sérgio Fukunaga, para permanecer em uma arte marcial "a pessoa procura um pouquinho de disciplina e gosta da doutrina também, da hierarquia e coisas do estilo". Segundo Aries (1998) e Lee (2007), a motivação para a prática da arte marcial, quando baseada em princípios corretos, influencia no caráter do praticante. As artes marciais vinculam-se com princípios filosóficos ou rituais religiosos como o budismo, taoismo, xintoísmo e confucionismo, que estão intimamente arraigadas na cultura de povos do extremo oriente, a exemplo da China e Japão (ARIES, 1998; LEE, 2007). Ao incorporarem tais elementos, as artes marciais visam preparar o sujeito física e espiritualmente e, deste modo, seu aprimoramento como ser humano.

Quanto a dinâmica de campeonatos e treinos, que, conforme observado nos jornais, tem acompanhado o desenvolvimento do sumô na Colônia Japonesa de Ivoti desde a década de 1990, há um preparo que inicia normalmente no mês de março em decorrência do campeonato gaúcho que ocorre em abril. É adotada uma frequência semanal de treinos com os atletas que competem em todo o estado. Em decorrência das distâncias de deslocamento, tendo em vista que alguns atletas moram em Capão da Canoa, Itati, Nova Petrópolis, São Leopoldo e Esteio, torna-se difícil haver encontros mais do que uma vez por semana. Desta forma, os atletas se reúnem geralmente aos sábados ou domingos, dependendo de um acordo. Já o campeonato brasileiro ocorre em julho, e para este evento é adotada uma dinâmica semelhante, com reuniões semanais que ocorrem em dohyos variados e não só em Ivoti. Há uma rotação entre os quatro dohyos do estado, o de Ivoti, de Gravataí, de Nova Petrópolis e de Itati (FUKUNAGA, 2017). 
Na colônia japonesa de Itati, a primeira referência sobre o sumô menciona o ano de 2008, quando foi realizado o $48^{\circ}$ campeonato gaúcho da modalidade. Além da equipe de Itati, estava presente a equipe de Nova Petrópolis, campeã da competição (EQUIPE..., 2008). No ano seguinte, a cidade foi novamente sede do evento, atraindo espectadores e 45 atletas de todo o estado. Anos depois, em 2012 foi transmitida uma reportagem no Programa Zona de Impacto da Rede Globo, veiculado na SPORTV, sobre os atletas da cidade de Itati, treinados por Jorge Yutaka Takimoto conhecido como "Botian" (SUMÔ, 2012). O programa apontou que o sumô ocorria no ginásio da Associação Cultural e Esportiva de Itati $(\mathrm{ACEI})^{17}$, com frequência média de cinco vezes por semana, sob a orientação de Botian. De acordo com as informações do programa, pode-se sugerir que as competições orientavam a prática do sumô na ACEI em Itati. Naquele momento, os atletas treinavam sistematicamente para o campeonato gaúcho que aconteceria em março daquele ano e depois continuariam os treinos para participarem da seletiva do campeonato brasileiro, disputado São Paulo. O sumô enquanto prática entre as crianças da comunidade, filhos de nipo-brasileiros e sumotoris, foi também evidenciado na reportagem. Assim como salienta Fukunaga, para o professor Botian, a prática do sumô atua como representação da cultura japonesa na cidade de Itati: "Como nós estamos há 40 anos aqui em Itati, essa cultura a gente cultiva ainda, que é a luta de sumô em cima do dohyo simples que é este ringue".

Cabe salientar que apesar da presença majoritária de homens nas fontes consultadas, também são encontradas mulheres praticantes de sumô em Ivoti e em outras localidades do Rio Grande do Sul. Todavia, o quantitativo de mulheres praticantes parece ser muito inferir quando comparado ao dos homens. Isto pode estar associado ao desenvolvimento da prática do sumô no Japão. A despeito dos campeonatos mundiais e da participação delas nos mesmos, como já destacado, no Japão a prática do sumô por mulheres é oficialmente vetada, pois, para os tradicionalistas isto representaria "o fim do sumô" (GOMES, 2008).

Na atualidade, o desenvolvimento do sumô em Ivoti e no Rio Grande do Sul, tem se expandido, ainda que de forma discreta, para além dos círculos de nipo-brasileiros. Os novos e diversificados meios de comunicação facilitam esta difusão. Praticantes têm divulgado entre os amigos, alguns já utilizam redes sociais para postar treinos e divulgar campeonatos, ocasionado um interesse maior pelas pessoas que admiram tanto artes marciais quanto a cultura japonesa. Para Fukunaga (2017), embora na atualidade já tenha descendentes de imigrantes alemães de Nova Petrópolis e um rapaz de Capão da Canoa dentre os praticantes que ele conhece, o grupo que constitui o sumô no estado é ainda muito restrito. Complementando esta ideia, em sua opinião o sumô tem "variado" bastante os praticantes devido a estes novos adeptos, mesmo que ainda exista aquele preconceito "de usar uma fralda, que é meio pejorativo, mas quem gosta fica. Não adianta" (FUKUNAGA, 2017). Gradativamente os nipo-brasileiros e teuto-brasileiros integraram as etnias e as manifestações culturais, incluindo os momentos em que passaram a compartilhar

17 A ACEI foi idealizada em 03 de julho de 1987 (EMPRESAS DO BRASIL, 2015). Localizada na Rua Nestor Becker, S.N no centro do município de Itati é uma entidade de caráter cultural e esportiva, de direito privado e sem fins lucrativos (PREFEITURA..., 2013). 
festividades que garantiram uma convivência harmoniosa entre estes povos que tinham o objetivo comum de reconstruir suas vidas em uma nova terra.

\section{CONSIDERAÇÕES FINAIS}

Os vestígios encontrados indicam que para manter o contato com os conterrâneos e preservar elementos de uma origem japonesa, os moradores da colônia passaram a desenvolver práticas corporais, dentre as quais se destaca o sumô. Evidenciou-se que a prática do sumô, em diferentes momentos, foi apropriada como meio de representar a comunidade e uma identidade nipônica em meio a um espaço circundado por representações teuto-brasileiras. Ademais, a prática de luta representa, no meio familiar, uma tradição que é transmitida desde a infância.

A fim de manter viva uma cultura e estabelecer fronteiras - onde também foram tensionados contatos e estabelecidos câmbios culturais - os imigrantes e descendentes de japoneses de Ivoti se organizaram e criaram estratégias de pertencimento e promoção da coletividade, como a Associação Cultural e Esportiva Nipo-Brasileira de Ivoti (ACENB), fundada em 1981. Este local concebe uma das principais formas de promoção de suas atividades culturais e de preservação de representações identitárias. Diante deste contexto, percebe-se a relevância deste espaço como lugar de compartilhamentos e de produção de uma memória coletiva na colônia a partir de um passado comum.

Os significados compartilhados no sumô pela colônia japonesa acompanham a realidade dos sumotoris brasileiros, na condição de amadores. As primeiras evidências encontradas nas fontes consultadas acerca do sumô abordam o contexto de campeonatos que reuniam lutadores não só de Ivoti, mas de outras cidades como São Leopoldo, Nova Petrópolis e Gravataí. Logo, sugere-se que os eventos e campeonatos promovidos na ACENB são momentos particularmente importantes de reunião e trocas entre nipo-brasileiros de diferentes localidades no Rio Grande do Sul. Ainda, cabe salientar que, na atualidade, o sumô tem atraído, também, praticantes e espectadores não descendentes de japoneses.

Por meio de algumas particularidades observadas nas imagens pertencentes aos jornais consultados podemos refletir acerca das representações da prática do sumô ao levar em conta suas diferentes formas vivenciadas. Enquanto as representações do sumô na perspectiva de esporte profissional estão circunscritas a um contexto mais tradicional, que exige uma maior rigidez de comportamentos por parte dos lutadores, bem como dos aspectos religiosos do shintoísmo observados nos dohyos do Japão, em Ivoti estes detaIhes não foram percebidos. A fim de adaptarem-se a uma diferente realidade, a prática do sumô na colônia japonesa, assim como na maior parte do Brasil, permite que os lutadores utilizem bermudas ou sungas por baixo do mawashi.

Em Ivoti, os contatos culturais e seus tensionamentos provocaram outras transformações e a necessidade de adaptação, de reinvenção desta cultura, o que desta forma os auxiliava a se reafirmar em solo étnico de diferente ascendência. Esta relação permitiu que os imigrantes japoneses da Colônia de Ivoti, mesmo em um espaço com demarcações 
simbólicas fortemente construídas pela identidade teuto-brasileira, pudessem manifestar e ressignificar tanto sua identidade quanto suas práticas culturais e, dentre estas, as corporais.

Sugere-se, enfim, a realização de mais estudos, em locais e períodos específicos, que construam diferentes versões e ressaltem significados apropriados pela e na prática do sumô. Salienta-se aqui a importância de estudos sobre as artes marciais no Brasil, em especial àquelas que ainda são pouco representadas pelos artigos acadêmicos e livros didáticos, a fim de produzir processos educativos para o conhecimento e o reconhecimento da diversidade de práticas corporais e esportivas que compõe o cenário brasileiro.

\section{REFERÊNCIAS}

A COLÔNIA Japonesa no futebol. Jornal de Ivoti. Ivoti, p. 16. nov. 1985.

ÁRIES, Marcos Antônio. A origem das artes marciais: O seu Simbolismo Como Veículo de Iluminação. Itabuna: Gráfica Colorpress, 1998.

CAMPEONATO de sumô na Colônia Japonesa. Jornal Livre Expressão. Ivoti, p. 6. 28 fev. 1996.

CAMPEONATO de Sumô. O Diário. Ivoti, p. 1. 28 abr. 2003.

CANTARINO FILHO, Mario Ribeiro; MIURA, Hiromi. Japão e Brasília: imigração e esporte. Brasília: Thesaurus Editora, 2010.

CELLARD, André. A análise documental. In: POUPART, Jean et al (Org.). A pesquisa qualitativa: enfoques epistemológicos e metodológicos. Petrópolis: Vozes, 2008. p. 295-316.

CHARTIER, Roger. A história cultural: entre práticas e representações. Rio de Janeiro: Bertrand Brasil, 2000.

COLÔNIA Japonesa. Jornal Livre Expressão. Ivoti, p. 9. 17 jan. 1995.

COLÔNIA Japonesa recebe melhorias. Jornal Livre Expressão. Ivoti, p. 6. jun. 1996.

DARIDO, Suraya Cristina. Educação Física Escolar: compartilhando experiências. São Paulo: Phorte, 2011.

DILLY, Gabriela; GEVEHR, Daniel Luciano. Para não espetacularizar o passado: memória, identidade étnica e educação patrimonial na construção do Memorial da Colônia Japonesa de Ivoti. Colóquio - Revista de Desenvolvimento Regional - Faccat, Taquara, v. 11, n. 2, p.55-70, 2014.

EMPRESAS DO BRASIL (Brasil). Cadastro Nacional. ACEl. Disponível em: < https:// empresasdobrasil.com/empresa/acei-90938259000170 > . Acesso em: 13 nov. 2016.

EQUIPE Nova Petrópolis é campeã gaúcha de Sumô. O Diário. Ivoti, p. 59. 25 abr. 2008.

ESTADUAL de sumô. O Diário da Encosta da Serra. Ivoti, p. 25. 30 abr. 2014, FEIRA NA COLÔNIA. O Diário da Encosta da Serra. Ivoti, p. 6. 31 mar. 2014. FRÉDERIC, Louis. O Japão: Dicionário e Civilização. São Paulo: Globo, 2008.

FROSI, Tiago Oviedo. Uma história do karate-do no Rio Grande do Sul: de arte marcial a prática esportiva. 2012. 224 f. Dissertação (Mestrado em Ciências do Movimento Humano) - Escola de Educação Física da Universidade Federal do Rio Grande do Sul, 2012. 
FUKUNAGA, Sérgio. Entrevista. Concedida à Josiana Ayala Ledur. 01 de maio de 2017. Transcrição: Josiana Ayala Ledur.

GAUDIOSO, Tomoko Kimura. O trabalho temporário no Japão e seu reflexo na estrutura familiar da colônia de Ivoti. In: X Reunião de Antropologia do Mercosul, Curitiba, 2011.

GOMES, Fábio José Cardias. Quatro histórias e uma epifania: estudos interdisciplinares acerca do budô japonês. Dialogia, São Paulo, v. 7, n.1, p. 41-51, 2008.

HALL, Mina. The big book of sumo: History, Practice, Ritual, Fight. Albany: Stone Bridge Press, 1997.

HANDA, Tomoo. O imigrante Japonês: história de sua vida no Brasil. São Paulo: Ed. T. A Queiroz e Centro de Estudos Nipo-brasileiro, 1987.

HIGUCHI, Taka. Itati na Globo: Sumô no Brasil. 2011. Disponível em: < http://sumobrasileiro. blogspot.com.br/2011/02/itati-na-globo.html > . Acesso em: 13 maio 2017.

HIRATA, Ricardo Yoshiyuki. Tempo e Espaço na Dinâmica Migratória Japonesa: o Caso de Mogi das Cruzes. 2005. 175 f. Dissertação (Mestrado) - Programa de PósGraduação em Estudos Populacionais e Pesquisas Sociais, Escola Nacional de Ciências Estatísticas, Rio de Janeiro, 2005. Disponível em: < http://www.dominiopublico.gov. $\mathrm{br} /$ pesquisa/DetalheObraForm.do?select_action $=\&$ co_obra $=128614>$. Acesso em: 17 set. 2017.

IFS. International Sumo Federation. A Brief Introduction to the International Sumo Federation and to the sport of Amateur Sumo. Disponível em: < http://www.ifs-sumo. org/ifs-recognised.html>. Acesso em: 02 fev. 2017.

IRMÃOS Sato brilham no sumô. Folha do Povo. Sapucaia do Sul e Esteio, p. 16-16. 27 ago. 2014.

JICA. Japan Internacional Cooperation Agency. Os nikkeis e a sociedade brasileira nos próximos 20 anos. Relatório da Comissão da São Paulo, 2003.

KOSSOY, Boris. Fotografia \& História. São Paulo: Ateliê Editorial, 2001.

LEDUR, Josiana Ayala. Práticas corporais na colônia japonesa de Ivoti, Rio Grande do Sul (década de 1980 à década de 2010). 2017. 136 f. Dissertação (Mestrado) - Curso de Ciências do Movimento Humano, Escola de Educação Física, Fisioterapia e Dança, Universidade Federal do Rio Grande do Sul, Porto Alegre, 2017.

LEDUR, Josiana Ayala; CARMONA, Eduardo Klein; MAZO, Janice Zarpellon. Karate GojuRyu no Rio Grande do Sul: revisitando a vida de Akira Taniguchi. Recorde: Revista de História do Esporte, Rio de Janeiro, v. 6, n. 2, p.1-23, 2013.

LEE, Bruce. Aforismos. São Paulo: Conrad Editora do Brasil, 2007.

MATOS, Júlia Silveira; SENNA, Adriana Kivanski. História oral como fonte: problemas e métodos. Historiae, Rio Grande, v. 2, n. 1, p. 95-108, 2011.

MEIHY, José Carlos Sebe B. Manual de História Oral. São Paulo: Edições Loyola, 2002.

MELLO, Suzi. Feira na Colônia Japonesa já recebeu 10 mil visitantes este ano. Jornal NH. Novo Hamburgo, p. 1-2. 24 abr. 2016.

MOCARZEL, Rafael Carvalho da Silva. Relatos sobre o sumô ontem e hoje no Brasil e no mundo. Revista Kinesis, vol. 34, n. 2, p. 104-116, 2016. 
MULLER, Elio Eugênio. Gente de Dois Mundos: 25 Anos da Colônia Japonesa de Itati. Livreto Popular nº 02. Curitiba: Italprint, 1993.

NETO, Helena Brum; BEZZI, Meri Lourdes. Regiões culturais: a construção de Identidades culturais no Rio Grande Do Sul e sua manifestação na paisagem gaúcha. Revista Sociedade \& Natureza, Uberlândia, v. 20, n. 2, p. 135-155, dez. 2008.

NUNES, Alexandre Velly. A influência da imigração japonesa no desenvolvimento do judô brasileiro: uma genealogia dos atletas brasileiros medalhistas em Jogos Olímpicos e campeonatos mundiais. 2011. 198 f. Tese (Doutorado) - Curso de Pedagogia do Movimento Humano, Escola de Educação Física e Esporte, Universidade de São Paulo, São Paulo, 2011.

PESAVENTO, Sandra. História \& História Cultural. Belo Horizonte: Autêntica, 2008.

PREFEITURA DE ITATI (Município). Lei nº 880, de 17 de julho de 2013. Subvenção Social Acei. Itati, RS.

RODRIGUES JÚNIOR, Cid Corrêa. Cid Rodrigues Júnior fala sobre a vivência com o Sensei Lacerda: Portal do Judô. 2012. Disponível em: < https://portaldojudobrasileiro. wordpress.com/2012/07/03/sensei-lacerda-por-cid-rodrigues-junior/ > . Acesso em: 08 fev. 2017.

SANTOS, Geraldine Alves; DOLL, Johannes; GAUDIOSO, Tomoko Kimura. A integração cultural do Japonês na cultura brasileira: a experiência da Colônia de Ivoti. Cadernos do Programa de Pós-graduação em Direito, Porto Alegre, v. 1, n. 3, p.53-62, 2003. Edição Especial.

SANTOS, Fábio José. O Sumô no Brasil. Revista Digital Especializada Livre Esportes, 2012.

Disponível em: < http://www.livresportes.com.br/reportagem/o-sumo-no-brasil>. Acesso em: 23 mar. 2017.

SOMMA, Isabelle. leyasu Togugawa: o destemido senhor da guerra. Revista aventuras na história para viajar no tempo, p. 26-33, 2005.

SUMÔ. Realização de Encontro Com Fátima Bernardees. Rio de Janeiro: Rede Globo, 2014. Programa de TV., son., color.

SUMÔ em Itati. Realização de Zona de Impacto. 2012. Rio de Janeiro: SportTV. 2012. Programa de TV., son., color.

SOCIAL e esporte. Banner de divulgação encontrado no Memorial da Colônia Japonesa de Ivoti, 2016.

SUZUKI, Frank Shiguemitsu; MIRANDA, Maria Luiza de Jesus. A história da imigração japonesa e seus descendentes: prática de atividade física e aspectos sócio-culturais. Conexões: Revista da Faculdade de Educação Física da Unicamp, Campinas, v. 6, ed. especial, p. 409-418, jul. 2008.

VERÍSSIMO, Arthur. Segura essa. Revista Gol Linhas Aéreas inteligentes, $\mathrm{n}^{\circ} 158$, p. 84, 2015. 